\title{
The protective effects of emulsified isoflurane on myocardial ischemia and reperfusion injury in rats
}

\author{
Zhao-Yang Hu, PhD $\cdot$ Nan-Fu Luo, MB $\cdot$ Jin Liu, MD
}

Received: 26 May 2008/Revised: 24 September 2008/Accepted: 14 November 2008/Published online: 31 December 2008

(C) Canadian Anesthesiologists' Society 2008

\begin{abstract}
Purpose Pretreatment with volatile anesthetics has been demonstrated to exert cardioprotective effects. The purpose of this study was to examine the effect of emulsified isoflurane, a new formulation of isoflurane in lipid emulsion, administered intravenously in an ischemia and reperfusion model of myocardial injury.

Methods Thirty-two Sprague Dawley rats of both sexes were subjected to $30 \mathrm{~min}$ of myocardial ischemia followed by 180 min of reperfusion. Each was assigned to one of four pretreatment groups to receive an isovolumetric intravenous infusion of saline: control group, $30 \%$ intralipid group, $8 \%$ emulsified isoflurane $2 \mathrm{ml} \mathrm{kg}^{-1}$ group, and sham group (each group, $n=8$ ). The vehicles were administered at a constant rate for $30 \mathrm{~min}$ and then discontinued 30 min before left anterior descending coronary artery occlusion. The cardioprotective effects were examined by determining hemodynamics, infarct size, enzyme activity, and cardiomyocytic apoptosis.
\end{abstract}

Results Pretreatment with emulsified isoflurane $2 \mathrm{ml} \mathrm{kg}^{-1}(P=0.000)$ significantly reduced infarct size $(22.6 \pm 2.2 \%)$ compared with control $(34.8 \pm 2.3 \%)$ and $30 \%$ intralipid $(31.1 \pm 2.9 \%)$. When compared with the control and intralipid groups, emulsified isoflurane increased Bcl-2 expression while decreasing Bax and

Z.-Y. Hu, PhD · N.-F. Luo, MB · J. Liu, MD ( $ه)$

Department of Anesthesiology, West China Hospital,

Sichuan University, Chengdu 610041, Sichuan,

People's Republic of China

e-mail: scuanesth@hotmail.com

J. Liu, MD

The State Key Laboratory of Biotherapy of Cancer,

West China Hospital, Sichuan University, Chengdu,

Sichuan, People's Republic of China
Caspase-3 expression and enhancing Bcl-2/Bax ratios. The apoptotic index in the emulsified isoflurane treatment group showed a significant reduction compared with that in the control group $(P=0.000)$ and the intralipid group $(P=0.001)$. In addition, the serum levels of lactate dehydrogenase and creatine kinase were markedly reduced in the emulsified isoflurane treatment group compared with the control and intralipid groups (lactate dehydrogenase, $P=0.015$ vs. control; creatine kinase, $P=0.000$ vs. control and intralipid).

Conclusion These data support a cardioprotective effect of intravenous emulsified isoflurane against myocardial ischemia and reperfusion injury, which are mediated, at least in part, by the inhibition of apoptosis and cell damage.

\section{Résumé}

Objectif Il a été démontré que les agents anesthésiques volatils exercent un effet cardioprotecteur lorsqu'ils sont administrés en traitement préventif. L'objectif de cette étude était d'examiner l'effet d'une émulsion d'isoflurane, une nouvelle formulation d'isoflurane en émulsion lipidique, administrée par voie intraveineuse dans un modèle d'ischémie reperfusion de lésion myocardique.

Méthode Trente-deux rats Sprague Dawley des deux sexes ont été soumis à 30 min d'ischémie myocardique suivie de $180 \mathrm{~min}$ de reperfusion. Chaque rat a été randomisé dans l'un des quatre groupes de prétraitement suivants, recevant tous une perfusion intraveineuse isovolumétrique de solution saline: groupe témoin, groupe intralipide 30\%, groupe émulsion d'isoflurane $8 \% 2 \mathrm{~mL}$ $\mathrm{kg}^{-1}$, et groupe sans intervention (pour chaque groupe, $n=8)$. Les véhicules ont été administrés à un taux constant durant $30 \mathrm{~min}$ puis interrompu $30 \mathrm{~min}$ avant l'occlusion de l'artère coronaire descendante antérieure 
gauche. Les effets cardioprotecteurs ont été examinés en évaluant l'hémodynamie, la taille de l'infarctus, l'activité enzymatique et l'apoptose des cardiomyocytes.

Résultats Dans le groupe prétraitement avec une émulsion d'isoflurane $2 \mathrm{~mL} \cdot \mathrm{kg}^{-1}(P=0,000)$, la taille de l'infarctus $(22,6 \pm 2,2 \%)$ a été significativement réduite comparativement aux groupes témoin (34,8 $\pm 2,3 \%)$ et intralipide $30 \%(31,1 \pm 2,9 \%)$. Lorsque comparé aux groupes témoin et intralipide, l'émulsion d'isoflurane a augmenté l'expression de Bcl-2 tout en réduisant l'expression de Bax et de Caspase-3 et en augmentant les ratios Bcl-1/Bax. L'index apoptotique dans le groupe de traitement à l'émulsion d'isoflurane a montré une réduction significative comparativement à celui du groupe témoin $(P=0,000)$ et du groupe intralipide $(P=0,001)$. De plus, les niveaux sériques de lactate-déshydrogénase et de créatine-kinase étaient significativement réduits dans le groupe de traitement à l'émulsion d'isoflurane comparativement aux groupes témoin et intralipide (lactatedéshydrogénase, $P=0,015$ vs témoin; créatine-kinase, $P=0,000$ vs témoin et intralipide).

Conclusion Ces résultats soutiennent l'hypothèse qu'une émulsion d'isoflurane intraveineuse a un effet cardioprotecteur contre l'ischémie myocardique et les lésions de reperfusion, lesquelles sont médiées, au moins en partie, par l'inhibition de l'apoptose et les lésions cellulaires.

Pretreatment with volatile anesthetics has repeatedly been shown to have direct cardioprotective effects against reversible or irreversible myocardial ischemia and reperfusion (I/R) injury by attenuating myocardial stunning, decreasing infarct size, and ameliorating contractile and diastolic functions. ${ }^{1,2}$ The underlying cellular and molecular mechanisms involved are not thoroughly understood, but the overall mechanism, which has been the focus of intense investigation, is likely multifactorial.

Emulsified isoflurane is a recently developed formulation that can be administered intravenously rather than as an inhalant, as was the traditional practice for this anesthetic. However, it has never been subjected to any cardiac preconditioning study until Chiari et al. ${ }^{3}$ recently demonstrated that $6.9 \%$ emulsified isoflurane produced preconditioning against infarction similar to ischemic preconditioning (IPC) in rabbits. Subsequently, our laboratory confirmed that $8 \%$ emulsified isoflurane produced preconditioning effects against I/R injury similar to the effects of inhaled isoflurane in rabbits. ${ }^{4}$

Nevertheless, the potential mechanisms involved in the cardioprotection afforded by intravenous emulsified isoflurane have never been valuated systematically. Evidence has suggested that anesthetic-induced preconditioning and IPC have many fundamental steps in common, including modulating the opening of the adenosine triphosphate-sensitive potassium channels, activating a second messenger signal system, protein kinases, generating reactive oxygen species, and maintaining $\mathrm{Ca}^{2+}$ homeostasis. ${ }^{1,2}$ Additionally, IPC was found to decrease myocardial infarction by reducing apoptosis. ${ }^{5,6}$ Emerging evidence has indicated that isoflurane may suppress apoptosis in the isolated cardiac myocytes in rats. ${ }^{7,8}$ These findings prompted us to postulate that emulsified isoflurane might also protect the heart against I/R injury by the influence of apoptosis, thereby shifting the balance in myocardial cells towards survival.

This investigation with an in vivo rat model aimed to determine: 1) whether administering emulsified isoflurane preconditions the heart; and 2) whether administering emulsified isoflurane, prior to regional myocardial ischemia, inhibits myocardial apoptosis.

\section{Methods}

All experimental protocols and procedures conducted in this investigation were approved by the Institutional Animal Care and Use Committee of Sichuan University (Sichuan, China). Thirty-two adult Sprague Dawley rats of both sexes, approximately 10 weeks old, and weighing 220-250 g were used in the present study. The animals were given free access to food and water and were kept under controlled conditions, i.e., temperature $\left(20-25^{\circ} \mathrm{C}\right)$, humidity $(60 \pm 5 \%)$, and a 12 -h day and night cycle.

Preparation of emulsified isoflurane

Emulsified isoflurane $(8 \% \mathrm{Vol} / \mathrm{Vol})$, newly developed by our laboratory for intravenous access, ${ }^{9,10}$ is produced by Huarui Pharmaceutical Co., Chengdu, China. Thirty percent intralipid (Huarui Pharmacy, Ltd., Chengdu, China) was used to dissolve liquid isoflurane (Abbott Laboratories, Queenborough, Kent, UK) and served as the vehicle for the preparation of test suspensions for injection. The purity of emulsified isoflurane $(8 \% \mathrm{Vol} / \mathrm{Vol})$ was rechecked by gas chromatography at the beginning of the experiment (Aligent 4890 D; Tegent Technology Ltd., Shanghai, China), and the test solutions were freshly prepared by an independent researcher not involved in the study.

\section{General preparation}

Each rat was anesthetized with a single intraperitoneal injection of $1 \%$ sodium pentobarbital $5 \mathrm{ml} \mathrm{kg}^{-1}$. A tracheostomy was performed when the animal was unconscious, and the lungs were artificially ventilated by connecting the tracheal tubing to a rodent ventilator (tidal volume was 8 
$10 \mathrm{ml}$, frequency was 70-80 times per minute, and expiration:inspiration was 2:1) (DH-150, Medical Instrument Factory of Zhejiang University, Hangzhou, Zhejiang, China). The standard limb lead II configuration electrocardiographic system was attached subcutaneously by needle electrodes to record heart rate and to confirm STsegment changes during ischemia. A 24-G heparin-filled catheter (Spacelabs Medical, Inc., Redmond, WA, USA) was inserted from the right carotid artery to the left ventricle for measurement of hemodynamic parameters. A 20$G$ venous catheter (Spacelabs Medical, Inc., Redmond, WA, USA) filled with heparinized saline was inserted into the caudal vein for saline and drug infusion. A lateral leftsided thoracotomy was performed through the fourth intercostal space, followed by a pericardiotomy. Heparin $500 \mathrm{U}$ was intravenously administered immediately before occlusion. A segment of the left anterior descending coronary artery (LAD) was identified just distal to the first diagonal branch, and a 6-0 silk suture was passed and tightened around this artery, approximately halfway between the apex and the base, to form a reversible coronary artery occlusion. In the sham group, the suture was merely passed around the artery without tying it off. Successful myocardial ischemia was verified by the emergence of regional epicardial cyanosis and ST segment changes. The suture was loosened after $30 \mathrm{~min}$ of ischemia, and the ischemic myocardium was reperfused for $3 \mathrm{~h}$. Body temperature was maintained between 37 and $38^{\circ} \mathrm{C}$ with the aid of a heating lamp.

\section{Experimental protocol}

The experimental design is summarized in Fig. 1. After surgical preparation and instrumentation, the animals adapted for $20 \mathrm{~min}$ to reach a steady state for baseline measurements. Each of the thirty-two rats was randomly assigned to one of four pretreatment groups (each group, $n=8$ ) according to a computer-generated random number schedule; sham group (sham), control group (CON), 30\% intralipid group (IL), and the emulsified isoflurane $(8 \% \mathrm{Vol} /$ Vol) $2 \mathrm{ml} \mathrm{kg}^{-1}$ group (EIso). All rats received an isovolumetric intravenous continuous infusion $4 \mathrm{ml} \mathrm{kg}^{-1} \mathrm{~h}^{-1}$ of $0.9 \%$ physiological saline at a constant rate for $30 \mathrm{~min}$. The infusion was then discontinued for $30 \mathrm{~min}$ for the acute memory phase before being followed by a 30 min coronary artery occlusion (no occlusion in the sham group) and a subsequent $180 \mathrm{~min}$ of reperfusion.

Measurements of hemodynamics

Hemodynamic parameters, including heart rate, left ventricular systolic pressure (LVSP), left ventricular enddiastolic pressure (LVEDP), and maximum rate of increase/decrease in left ventricular pressure $( \pm \mathrm{dP} / \mathrm{dtmax})$, were continuously monitored in our study. Pressure signals were amplified and digitally converted from the end of the 24-G catheter (Spacelabs Medical, Inc., Redmond, WA, USA) sheath and were stored in the computer throughout the experiment by the connected calibrated pressure transducer with physiologic recorder (Biolap $420 \mathrm{E}^{+}$, Taimeng, Chengdu, China) via a heparin-saline solutionfilled plastic tube.

\section{Determination of myocardial infarct size}

At the end of the reperfusion, the LAD was re-occluded, and the left ventricular area at risk (AAR) for infarction was separated from the normal area, stained with Evans blue dye (Sigma Chemical Co., St. Louis, MO, USA), frozen, and cut into transverse slices of equal thickness

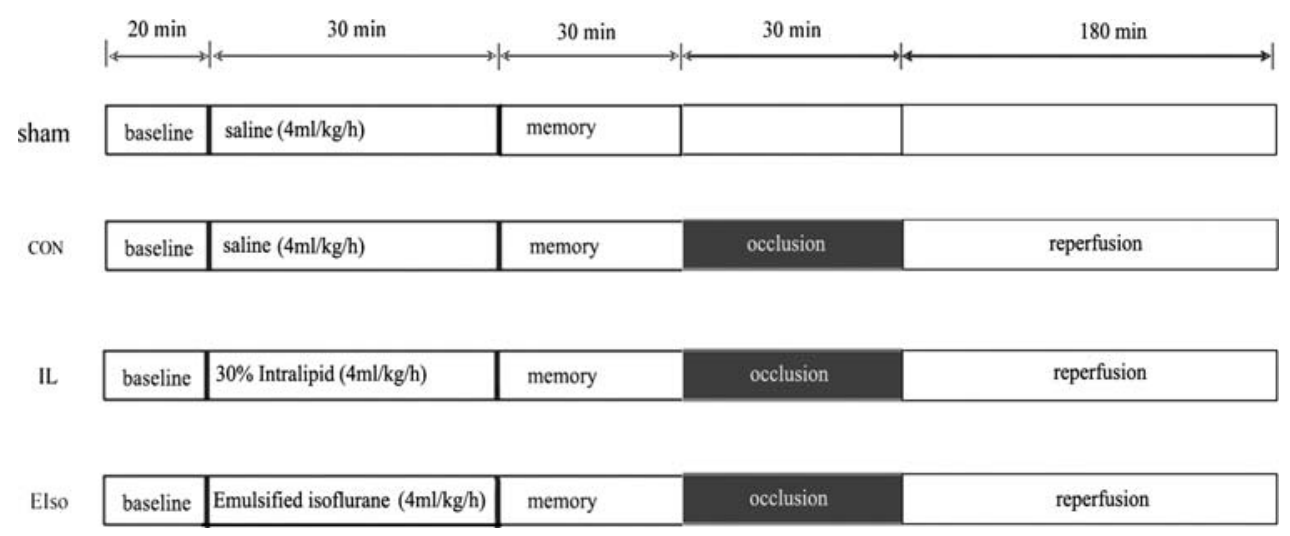

Fig. 1 Schematic illustration of experimental protocols. All rats in each group were given isovolumetric vehicle $\left(4 \mathrm{ml} \mathrm{kg}^{-1} \mathrm{~h}^{-1}\right)$. Shamoperated group (sham), rats received physiological saline with silk suture passing around the coronary. Physiological saline, $30 \%$ intralipid, and emulsified isoflurane $2 \mathrm{ml} \mathrm{kg}^{-1}$ were intravenously administered to control group (CON), intralipid group (IL), and emulsified isoflurane group (EIso) for $30 \mathrm{~min}$, followed by the $30 \mathrm{~min}$ memory phase. Next, the occlusion of the left anterior descending (LAD) coronary artery was maintained for $30 \mathrm{~min}$, followed by the 180 min of reperfusion ( $n=8$ per group) 
( $1 \mathrm{~mm})$. The slices were incubated at $37^{\circ} \mathrm{C}$ for $20 \mathrm{~min}$ in $1 \%$ triphenyltertrazolium chloride (Sigma Chemical Co., St. Louis, MO, USA) in $0.1 \mathrm{M}$ phosphate buffer adjusted to $\mathrm{pH}$ 7.4. After fixation by $4 \%$ paraformaldehyde for $24 \mathrm{~h}$, the infarcted and the non-infarcted myocardia within the AAR were carefully separated and weighed. Infarct size was expressed as a percentage of the AAR.

Measurement of cellular injury

At the end of the experiment, serum levels of lactate dehydrogenase $(\mathrm{LDH})$ and creatine kinase $(\mathrm{CK})$ were determined spectrophotometrically by cytotoxicity detection LDH, CK kits (Nanjing Jiancheng Biological Product, Nanjing, China) according to the manufacturer instructions using a UV spectrophotometer (Model UV-2401PC; Shimadzu Co., Kyoto, Japan). All samples and standards were measured in duplicate.

Tissue collection

A separate set of parallel experimental animals were used for immunohistochemical studies and apoptosis evaluation ( $n=8$ per group). At the end of the 180 min reperfusion, LAD relegation was followed by an infusion of $2 \mathrm{ml}$ of $1 \%$ Evans blue dye to delineate the left ventricular AAR zone from the normal area. The heart was then dissected and sliced into 2-mm-thick sections parallel to the atrioventricular groove. The atria and the right ventricle were removed. Transverse sections of the heart were rinsed in saline, blotted onto filter paper, and dried. Next, they were immersed overnight in $10 \%$ phosphate buffered formalin at room temperature. The heart sections were then fixed in formaldehyde, dehydrated, and embedded in paraffin. The hearts were sliced into $5 \mu \mathrm{m}$ thick sections, consecutively. Serial sections of transverse myocardial slices, which included the left ventricular walls and the septum from each heart, were mounted on glass slides for immunohistochemical analysis and apoptosis measurement. All analyses and measurements of pro- and anti-apoptotic proteins and terminal deoxynucleotidyl transferase-mediated dUTP nick-end labelling (TUNEL) assay were performed by a single researcher blinded to the treatment group.

Immunohistochemical procedure and evaluation

The expression of Bcl-2, Bax, and Caspase-3 proteins was detected with the immunohistochemical method. Heart sections of the non-ischemic and ischemic left ventricles were deparaffinized in xylene and isopropanol. Anti-Bcl-2, anti-Bax, and anti-Caspase- 3 antibodies (Santa Cruz Biotechnology, Santa Cruz, CA, USA) were used as the primary antibodies, and either biotinylated goat anti-rabbit
IgG (Bcl-2, Caspase-3) or goat anti-mouse IgG (Bax) antibody (Santa Cruz Biotechnology, Santa Cruz, CA, USA) was added as the second antibody for Bcl-2, Bax and Caspase- 3 immunohistochemical staining, followed by the addition of streptomyces anti-biotin protein-peroxidase solution. Tissues were stained with fresh 3, 3-diaminobenzene (Beijing Zhongshan Golden Bridge Biotechnology Co., Beijing, China) solution and counterstained with hematoxylin for microscopy. The anti-Bcl-2, Bax, or Caspase-3 protein antibodies were replaced by a phosphate buffer solution as negative control. Digital images were captured by an inverted microscope (CAST system, Olympus A/S, Ballerup, Denmark). Brown staining in the cytoplasm of cells was evaluated as positive expression. Ten visual sights were randomly selected for each slide to perform image analysis with Image-pro plus (Media Cybernetics Inc., Carlsbad, CA, USA). Statistical testing compared the ratio of the mean optic density to the area attained in the positive, i.e., the positive expressive index.

\section{Apoptosis measurements}

Terminal deoxynucleotidyl transferase-mediated dUTP nick-end labelling assay was adopted for the assessment of apoptotic cell death according to the manufacturer's protocol (Roche Diagnostics, Indianapolis, IN, USA). More than 20 different fields from each heart were chosen at random and blindly analyzed. The apoptotic index was judged as a percent of the number of TUNEL-positive cardiomyocytic apoptotic nuclei out of the total cardiomyocytic nuclei population. Images were obtained using the CAST system (Olympus A/S, Ballerup, Denmark) and analyzed with Image-pro plus (Media Cybernetics Inc., Carlsbad, CA, USA).

\section{Statistical analysis}

All data are expressed as mean \pm SD and were analyzed with SPSS 13.0 software for Windows (SPSS Inc., Chicago, IL, USA). The Kolmogorov-Smirnov test supported the assumption of normal distribution for all parameters. Homogeneity of variance was tested by the Levene's test. The statistical test for hemodynamic changes over time was performed by two-way repeated-measures analysis of variance (ANOVA), with group as a between-subjects factor and time as a within-subjects factor. Interactions between group and time (group $\times$ time interaction) were also tested. Mauchly's test to assess the sphericity assumption was performed. If the sphericity assumption was not met for the repeated measures factor, then the Greenhouse-Geisser correction was applied to adjust the degrees-of-freedom in order to correct the violations of the sphericity assumption, when appropriate. ${ }^{11}$ When statistically significant 
differences were identified for group-time interactions, the Bonferroni correction procedure was used for multiple comparisons at individual time points between groups. Otherwise, in the presence of a significant time effect with no significant group $\times$ time interactions, global conclusions were drawn and comparisons between time were performed. Statistical analyses of enzyme activity, protein expression, and TUNEL assay were performed by one-way ANOVA, after determining the homogeneity-of-variance assumption. If variances were equal, the Bonferroni test was examined post hoc for multiple comparisons; otherwise, the Dunnett's T3 test was applied. Statistical significance was defined as $P<0.05$.

The sample size for this study was determined using measures of variance from previous investigations. ${ }^{3,4}$ The criterion for significance alpha was set at 0.05 . Eight rats in each group would be sufficient to provide an $80 \%$ power to detect a conservative $20 \%$ reduction in infarct size with a standard deviation of $5 \%$.

\section{Results}

Hemodynamic function

Hemodynamic data are presented in the Table 1 . The results from 32 animals contributed to the final data. Repeatedmeasures ANOVA confirmed a statistically significant difference among sham, CON, IL, and EIso groups in LVSP $(P=0.003), \operatorname{LVEDP}(P=0.048), \mathrm{dP} / \mathrm{dtmax}(P=0.000)$, and $-\mathrm{dP} / \mathrm{dtmax}(P=0.000)$ over the period of measurement. There were significant interactions between group assignment and time for heart rate $(P=0.001)$, LVSP $(P=0.036), \mathrm{LVEDP}(P=0.048), \mathrm{dP} / \mathrm{dtmax}(P=0.000)$, and $-\mathrm{dP} / \mathrm{dtmax}(P=0.003)$. Under baseline conditions, no significant differences in systemic hemodynamics were observed among the groups. Heart rate decreased during the reperfusion period in the $\mathrm{CON}$, EIso and IL groups. Coronary artery occlusion was accompanied by a reduction of systolic function in LVSP and $\mathrm{dP} / \mathrm{dtmax}$ and an increase in LVEDP and $-\mathrm{dP} / \mathrm{dtmax}$, which indicated the depression of diastolic function compared with the sham group and the respective baseline values. However, no significant grouprelated differences were found in hemodynamics throughout the occlusion and reperfusion procedures among the CON, IL, and EIso groups.

\section{Myocardial infarct size}

After reperfusion, the myocardial infarct size expressed as the percentage of AAR was comparable among the experimental groups $(F=52.48, \quad P=0.000)$; Fig. 2 . Infarct size in the EIso group was $22.6 \pm 2.2 \%[95 \%$ confidence interval (CI), 20.8-24.5\%], smaller than both the CON group $34.8 \pm 2.3 \%$ (95\% CI, 32.9-36.6\%; $P=0.000)$ and the IL group $31.1 \pm 2.9 \%$ (95\% CI, 29.0$33.1 \% ; P=0.000)$. However, there was no statistical difference in infarct size between the IL and the CON groups $(P=0.114)$.

Lactate dehydrogenase and CK release

There were significant differences in CK and LDH activities among the experimental groups (CK: $F=46.41$, $P=0.000 ;$ LDH: $\mathrm{F}=20.90, P=0.000)$; Fig. 3 . CK activity was significantly increased after reperfusion, reaching the following values at $3 \mathrm{~h}$ of reperfusion: CON group $12.1 \pm 1.9 \mathrm{U} \mathrm{ml}^{-1}\left(95 \% \mathrm{CI}, 10.5-13.7 \mathrm{U} \mathrm{ml}^{-1}\right.$, $P=0.000)$, IL group $10.8 \pm 1.5 \mathrm{U} \mathrm{ml}^{-1}$ (95\% CI, 9.6$\left.12.0 \mathrm{U} \mathrm{ml}^{-1}, \quad P=0.000\right), \quad$ and EIso group $6.1 \pm 1.9 \mathrm{U} \mathrm{ml}^{-1}$ (95\% CI, 4.5-7.7 $\left.\mathrm{U} \mathrm{ml}^{-1}, P=0.011\right)$ as compared with the sham group $3.1 \pm 1.6 \mathrm{U} \mathrm{ml}^{-1}(95 \%$ CI, 1.8-4.5 $\mathrm{U} \mathrm{ml}^{-1}$ ). However, emulsified isoflurane could minimize the leakage of $\mathrm{CK}$ out of myocardial cells caused by $\mathrm{I} / \mathrm{R}(P=0.000$ vs. CON group and $P=0.000$ vs. IL group). There was no statistical difference between the CON group and the IL group $(P=0.954)$. Although serum LDH activities increased significantly after I/R injury in the CON $(P=0.001)$, IL $(P=0.004)$, and EIso groups $(P=0.021)$ compared with the sham group, significantly lower LDH levels, similar to $\mathrm{CK}$, were observed in the EIso group $(P=0.015)$ compared with the CON group.

Immunohistochemistry of Bcl-2, Bax, and Caspase-3 proteins

Bcl-2, Bax, and Caspase-3 immunoreactivity was detected in the ischemic and the non-ischemic myocardium in each group (Fig. 4). In the non-ischemic area, the cardiomyocytes contained very low levels of Bcl-2, Bax, and Caspase-3; no difference was found among groups in this area. However, substantial expression was observed among groups within the left ventricular area at risk (Bcl-2, $P=0.000$; Bax, $P=0.000$; Caspase-3, $P=0.000)$. The positive expression of $\mathrm{Bcl}-2$, Bax, and Caspase- 3 proteins was significantly increased in the CON, IL, and EIso groups as compared with the sham-operated group, and the Bcl-2/Bax ratios were also significantly increased. Compared with the CON and IL groups, the emulsified isoflurane $2 \mathrm{ml} \mathrm{kg}^{-1}$ significantly increased the expression of Bcl-2 protein ( $P=0.019$ vs. $\mathrm{CON} ; P=0.029$ vs. IL), decreased the expression of Bax proteins $(P=0.043$ vs. $\mathrm{CON})$ and Caspase- 3 proteins $(P=0.000$ vs. CON; $P=0.022$ vs. IL), and enhanced the increase of Bcl-2/Bax ratios ( $P=0.001$ vs. $\mathrm{CON} ; P=0.004$ vs. IL). No significant difference was found between the CON and IL 
Table 1 Hemodynamics

\begin{tabular}{|c|c|c|c|c|c|c|c|}
\hline \multirow[t]{2}{*}{ Variable } & \multirow[t]{2}{*}{ Baseline } & \multirow[t]{2}{*}{ Drug } & \multirow[t]{2}{*}{ Memory } & \multirow[t]{2}{*}{ Occlusion } & \multicolumn{3}{|l|}{ Reperfusion } \\
\hline & & & & & $1 \mathrm{~h}$ & $2 \mathrm{~h}$ & $3 \mathrm{~h}$ \\
\hline \multicolumn{8}{|c|}{ HR (beats $\mathrm{min}^{-1}$ ) } \\
\hline Sham & $370 \pm 45$ & $363 \pm 45$ & $359 \pm 44$ & $362 \pm 37$ & $336 \pm 38$ & $330 \pm 43^{\dagger}$ & $318 \pm 43^{\dagger \dagger}$ \\
\hline $\mathrm{CON}$ & $363 \pm 70$ & $373 \pm 53$ & $368 \pm 37$ & $322 \pm 62$ & $285 \pm 20^{*}$ & $256 \pm 17 *^{\#}$ & $234 \pm 37 * * \#$ \\
\hline EIso & $393 \pm 69$ & $378 \pm 80$ & $379 \pm 93$ & $372 \pm 78$ & $297 \pm 59^{* \#}$ & $289 \pm 66^{* \#}$ & $259 \pm 78 * \#$ \\
\hline IL & $378 \pm 48$ & $349 \pm 72$ & $382 \pm 49$ & $313 \pm 54$ & $311 \pm 31^{* \#}$ & $279 \pm 44^{* \#}$ & $255 \pm 34 * * \#$ \\
\hline \multicolumn{8}{|c|}{ LVSP $(\mathrm{mmHg})$} \\
\hline Sham & $151 \pm 16$ & $149 \pm 16$ & $148 \pm 16$ & $138 \pm 17^{\dagger}$ & $145 \pm 14^{\dagger \dagger}$ & $146 \pm 12^{\dagger}$ & $137 \pm 12^{\dagger+t}$ \\
\hline $\mathrm{CON}$ & $141 \pm 29$ & $131 \pm 25$ & $130 \pm 24$ & $97 \pm 28^{* \# \#}$ & $105 \pm 14^{* \# \#}$ & $110 \pm 10^{* \#}$ & $106 \pm 14 * \#$ \\
\hline EIso & $168 \pm 18$ & $166 \pm 17$ & $164 \pm 22$ & $120 \pm 12 * * \#$ & $129 \pm 24^{* \#}$ & $132 \pm 20^{* * \# \#}$ & $126 \pm 13^{* * \# \#}$ \\
\hline IL & $172 \pm 19$ & $165 \pm 16$ & $166 \pm 18$ & $125 \pm 5^{* * \# \#}$ & $137 \pm 17^{* * *}$ & $133 \pm 21^{* * \#}$ & $128 \pm 9^{* * \# \#}$ \\
\hline \multicolumn{8}{|c|}{ LVEDP $(\mathrm{mmHg})$} \\
\hline Sham & $2 \pm 1$ & $2 \pm 1$ & $2 \pm 1$ & $3 \pm 1^{t+}$ & $3 \pm 1^{\dagger}$ & $3 \pm 1^{\dagger *}$ & $3 \pm 1^{\dagger *}$ \\
\hline $\mathrm{CON}$ & $2 \pm 3$ & $3 \pm 2$ & $2 \pm 3$ & $8 \pm 3 * * \# \#$ & $9 \pm 6^{* \#}$ & $9 \pm 5^{* \#}$ & $10 \pm 6^{* \#}$ \\
\hline EIso & $0 \pm 2$ & $0 \pm 2$ & $1 \pm 2$ & $7 \pm 3 * * \#$ & $4 \pm 2 * *^{\#}$ & $5 \pm 2 * * \#$ & $5 \pm 2 * * \#$ \\
\hline IL & $2 \pm 3$ & $5 \pm 6$ & $2 \pm 4$ & $6 \pm 4^{* \# \#}$ & $8 \pm 4 * * \# \#$ & $6 \pm 3^{\#}$ & $6 \pm 3^{* \#}$ \\
\hline \multicolumn{8}{|c|}{ dP/dtmax $\left(m m H g s^{-1}\right)$} \\
\hline Sham & $7183 \pm 709$ & $7025 \pm 697$ & $7076 \pm 626$ & $6751 \pm 810^{\dagger *}$ & $6757 \pm 762^{\dagger+*}$ & $6677 \pm 724^{\dagger+}$ & $6094 \pm 1004^{\dagger+1+}$ \\
\hline $\mathrm{CON}$ & $8384 \pm 2474$ & $7353 \pm 2322$ & $8015 \pm 2406$ & $3975 \pm 1275^{* * \# \#}$ & $5307 \pm 1607 * \#$ & $5390 \pm 1805^{* \#}$ & $4932 \pm 1443^{* \# \#}$ \\
\hline EIso & $9650 \pm 1462$ & $9193 \pm 896$ & $9524 \pm 1232$ & $5315 \pm 1809^{* * \# \#}$ & $6351 \pm 1378^{* * \# \#}$ & $6531 \pm 1740 * * \# \#$ & $5571 \pm 1614 * * \# \#$ \\
\hline IL & $9600 \pm 1794$ & $8242 \pm 2225$ & $9323 \pm 2001$ & $6282 \pm 1518^{* * \#}$ & $7052 \pm 1356^{* \#}$ & $6577 \pm 1394 * * \#$ & $5724 \pm 1506^{* * \# \#}$ \\
\hline \multicolumn{8}{|c|}{$-d P / d t m a x\left(m m H g s^{-1}\right)$} \\
\hline Sham & $-5617 \pm 1213$ & $-5513 \pm 1184$ & $-5584 \pm 1205$ & $-5292 \pm 1093^{\dagger+t}$ & $-5377 \pm 1169^{\dagger+*}$ & $-5429 \pm 1214^{\dagger *}$ & $-5388 \pm 1279^{\dagger+* *}$ \\
\hline $\mathrm{CON}$ & $-6119 \pm 1961$ & $-5484 \pm 1383$ & $-5351 \pm 1582$ & $-3088 \pm 1792 * \#$ & $-3341 \pm 953^{* \# \#}$ & $-3096 \pm 723 * * \#$ & $-2683 \pm 934 * * \# \#$ \\
\hline EIso & $-6921 \pm 1539$ & $-6780 \pm 1620$ & $-6818 \pm 2199$ & $-3341 \pm 1401 * * \# \#$ & $-4139 \pm 1831 * \#$ & $-4013 \pm 2162^{* \#}$ & $-3342 \pm 1867 * * \# \#$ \\
\hline IL & $-7194 \pm 1539$ & $-5616 \pm 1620$ & $-6917 \pm 2091$ & $-3928 \pm 849 * * \#$ & $-4269 \pm 1131 * *^{\#}$ & $-4142 \pm 1194 * *^{\#}$ & $-3740 \pm 1057 * * \# \#$ \\
\hline
\end{tabular}

Data are expressed as mean \pm SD. $H R$ heart rate, CON control, EIso $2 \mathrm{ml} \mathrm{kg}^{-1}$ emulsified isoflurane, IL $30 \%$ intralipid, LVSP left ventricular systolic pressure, $L V E D P$ left ventricular end-diastolic pressure; $\pm d P /$ dtmax maximum rate of increase/decrease in left ventricular pressure. $n=8$ in each group. $* P<0.05$, ** $P<0.01$ vs. baseline; ${ }^{\dagger} P<0.05,{ }^{\dagger} P<0.01$ vs. control; ${ }^{\star} P<0.05$; ${ }^{\star} P<0.01$ vs. intralipid;

${ }^{\#} P<0.05,{ }^{\# \#} P<0.01$ vs. sham

groups. Furthermore, negative control showed no positive immunoreactivity.

Apoptosis studies

No TUNEL-positive cells were detected in the non-ischemic zone in the four groups after I/R. However, a number of positive cells were found within the left ventricular area at risk, and differences were found among groups in this area $(P=0.000)$. As shown in Fig. 5 , the ratio of apoptotic cardiomyocytes to the total number of cardiomyocytes was significantly reduced in the EIso group $(17.8 \pm 7.8 \%$, CI: $11.4-24.4)$ as compared with the CON group (38.0 $\pm 6.9 \%, \mathrm{CI}$ : $32.3-43.7, P=0.000)$ and the IL group $(32.0 \pm 4.9 \%, \mathrm{CI} ; 27.9-36.1, P=0.001)$. However, treatment with intralipid had no significant effect on cardiomyocytic apoptosis $(P=0.380$ vs. CON).

\section{Discussion}

This study provides convincing evidence for emulsified isoflurane-induced cardioprotection in the rat heart in vivo. The main findings are as follows: First, pretreatment with emulsified isoflurane $(8 \% \mathrm{Vol} / \mathrm{Vol}) 2 \mathrm{ml} \mathrm{kg}{ }^{-1}$, prior to a 30 min coronary occlusion and a subsequent $3 \mathrm{~h}$ reperfusion, reduced the myocardial infarct size. Second, the emulsified isoflurane suppressed I/R-induced myocardial apoptosis, which may involve modulation of the expression of pro- and anti-apoptotic proteins, specifically Bax, Caspase-3, and Bcl-2. Third, emulsified isoflurane attenuated the increase in serum CK and LDH concentrations.

Anesthetic-induced preconditioning, one of the most potent strategies available for myocardial protection, was initially proposed by Warltier. ${ }^{12}$ Isoflurane, both in vitro and in vivo, exerts strong cardioprotective effects to protect 


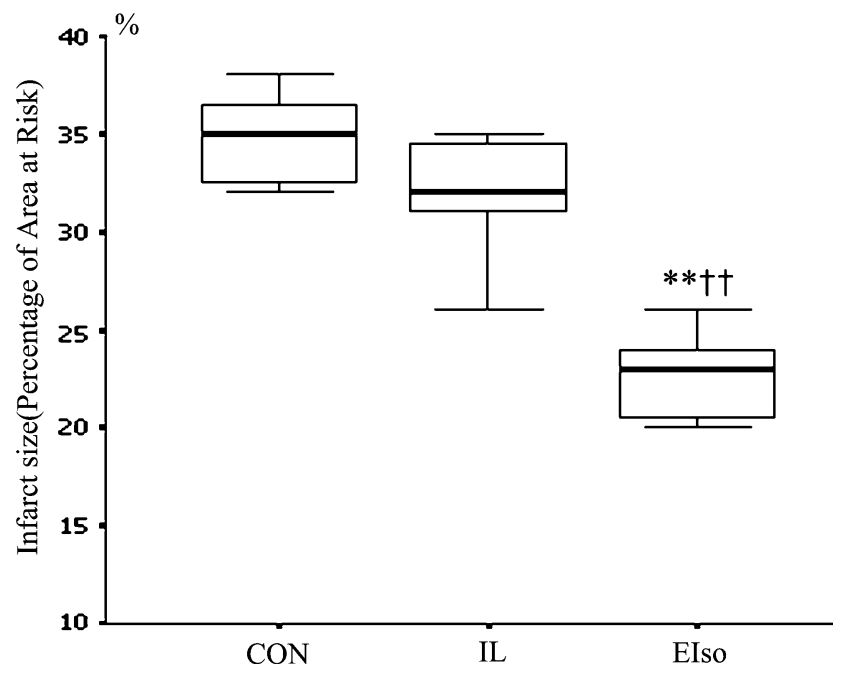

Fig. 2 Box-plot graph depicting myocardial infarct size as a percentage of the left ventricular area at risk in the control $(\mathrm{CON})$, intralipid (IL), and emulsified isoflurane $2 \mathrm{ml} \mathrm{kg}^{-1}$ (EIso) groups. The upper and lower edges of each box plot represent the 25th percentile and the 75th percentile, respectively. The line across each box represents the median value for the variable. Data are expressed as mean $\pm \mathrm{SD}$ ( $n=8$ per group). ${ }^{* *} P<0.01$ vs. CON group; ${ }^{\dagger \dagger}$ $P<0.01$ vs. IL group

myocardium against I/R injury. ${ }^{13,14}$ Previous investigations have demonstrated that pretreatment with emulsified isoflurane before prolonged coronary artery occlusion and reperfusion is capable of producing cardioprotection against infarction. For example, Chiari et al. ${ }^{3}$ reported that intravenous infusion of $6.9 \%$ emulsified isoflurane, at a constant rate of $3.5 \mathrm{ml} \mathrm{kg}^{-1} \mathrm{~h}^{-1}$ for $30 \mathrm{~min}$, produced acute and delayed preconditioning against myocardial infarction in rabbits. More recently, our laboratory demonstrated that a continuous infusion of $8 \%$ emulsified isoflurane to an end-tidal concentration of $0.64 \%$ reduced infarct size in rabbits. ${ }^{4}$ The current results also confirm these previous findings demonstrating that the administration of emulsified isoflurane $2 \mathrm{ml} \mathrm{kg}{ }^{-1}\left(4 \mathrm{ml} \mathrm{kg}^{-1} \mathrm{~h}^{-1}\right.$ for $30 \mathrm{~min}$ ) before ischemia induces cardioprotection against I/R injury. Additionally, our results indicate, for the first time, that emulsified isoflurane-induced preconditioning produces cardioprotection, and the inhibition of cardiac apoptosis may contribute to the protection.

The acute memory phase, an important temporal period between the preconditioning stimulus and the onset of the ischemia, allows the heart to remain resistant to prolonged infarction. In the study by Preckel et al., ${ }^{15}$ isoflurane had no effect on infarct size when administered only during the initial perfusion period. However, inhaled isoflurane has been shown to reduce infarct size in the acute memory phase in rats, ${ }^{16}$ rabbits, ${ }^{17}$ and $\operatorname{dogs}{ }^{18}$ when discontinued 15-30 min before LAD occlusion. $\mathrm{We}^{4}$ and others ${ }^{3}$ have previously demonstrated that emulsified isoflurane
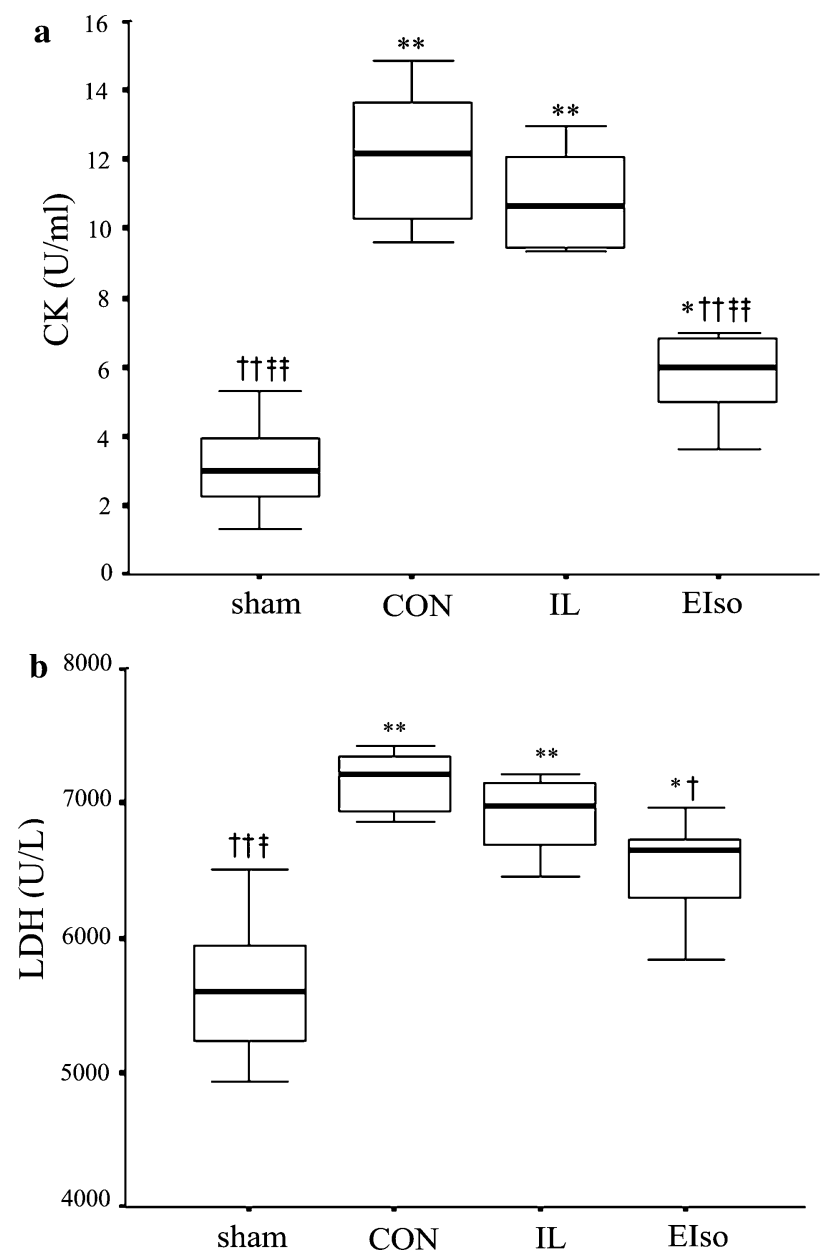

Fig. 3 Emulsified isoflurane attenuates serum levels of creatine kinase $(\mathrm{CK} ; \mathbf{a})$ and lactate dehydrogenase $(\mathrm{LDH} ; \mathbf{b})$ in rats subjected to $30 \mathrm{~min}$ of left anterior descending artery occlusion followed by $180 \mathrm{~min}$ of reperfusion ( $n=8$ per group). The data are displayed using a box-plot. Sham = sham-operation group; $\mathrm{CON}=$ control group; $\mathrm{IL}=30 \%$ intralipid group; EIso $=$ emulsified isoflurane $2 \mathrm{ml} \mathrm{kg}{ }^{-1}$ group. Data are mean $\pm \mathrm{SD}$. $* P<0.05$, $* * P<0.01 \mathrm{vs}$. sham group; ${ }^{\dagger} P<0.05,{ }^{\dagger} P<0.01$ vs. CON group; ${ }^{\star} P<0.05$, 柿 $P<0.01$ vs. IL group

produces cardioprotection. This beneficial action persists despite being discontinued before LAD occlusion, indicating that the emulsified isoflurane reserves another elimination period even as the initial 30 min preconditioning stimulus discontinues, which allows the myocardium to become increasingly resistant to subsequent prolonged ischemic insult. Furthermore, this protection is characterized by an acute memory period. Overall, therefore, it seems highly likely that the acute memory phase is associated with the observed protection offered by emulsified isoflurane in the myocardium, similar to that observed during IPC.

Our experiments were conducted during anesthesia with sodium pentobarbital. Pentobarbital has been shown to alter cardiac hemodynamics and performance in mice, ${ }^{19}$ 
Fig. 4 Comparison of expression of Bcl-2, Bax, and Caspase-3 protein in myocardium of rats in each group. a Bcl-2, Bax, and Caspase- 3 immunoreactivity in the cytoplasm of the myocytes of hearts, with and without occlusion. $\mathrm{CON}=$ control group, IL $=30 \%$ intralipid group, EIso $=$ emulsified isoflurane $2 \mathrm{ml} \mathrm{kg}^{-1}$ group (magnification $400 \times$ ). b The table illustrates the difference of Bcl-2, Bax, and Caspase-3 expression from sham hearts and hearts that underwent occlusion. Data are presented as mean \pm SD. Each group $n=8$. $\mathrm{PEI}=$ positive expressive index; $\mathrm{CI}=95 \%$ confidence interval. $* P<0.05, * * P<0.01$ vs. sham group; ${ }^{\dagger} P<0.05,{ }^{\dagger}$ $P<0.01$ vs. CON group; ${ }^{\sharp} P<0.05,{ }^{\star} P<0.01$ vs. IL group
Bcl-2

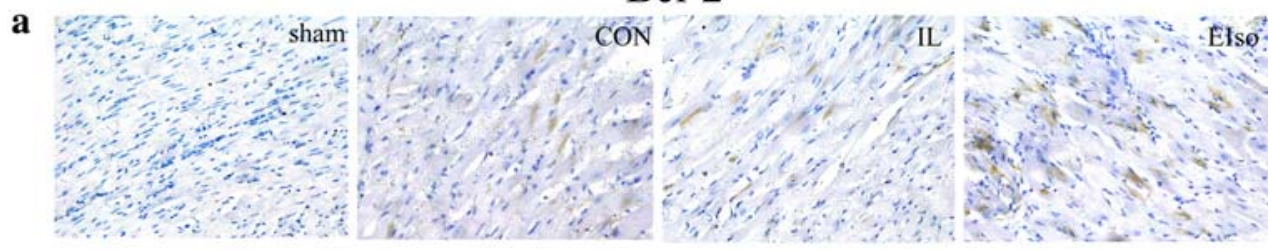

Bax

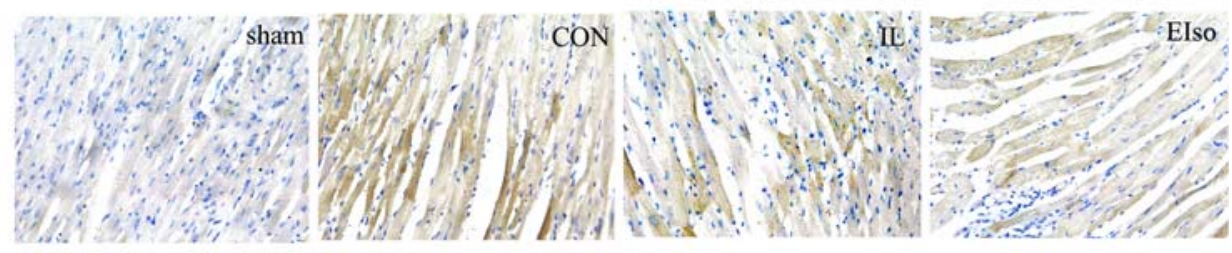

Caspase-3

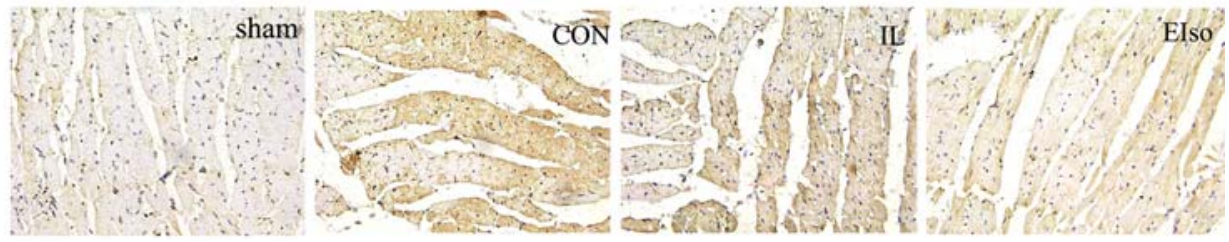

b

\begin{tabular}{|c|c|c|c|c|}
\hline & sham & $\mathrm{CON}$ & IL & EI \\
\hline Bcl-2(PEI) & $0.06 \pm 0.04 t+t$ & $0.15 \pm 0.09 *$ & $0.17 \pm 0.03 * *$ & $0.23 \pm 0.04 * * \dagger \dagger$ \\
\hline $\mathrm{CI}$ & $0.03-0.10$ & $0.07-0.22$ & $0.13-0.19$ & $0.19-0.27$ \\
\hline $\operatorname{Bax}(\mathrm{PEI})$ & $0.24 \pm 0.04 \dagger+t+t$ & $0.34 \pm 0.04 * *$ & $0.32 \pm 0.06 *$ & $0.29 \pm 0.04 \dagger$ \\
\hline $\mathrm{CI}$ & $0.20-0.28$ & $0.30-0.37$ & $0.27-0.38$ & $0.26-0.33$ \\
\hline $\mathrm{Bcl}-2 / \mathrm{Bax}$ & $\begin{array}{l}0.26 \pm 0.14 \div \\
0.15-0.38\end{array}$ & $\begin{array}{l}0.49 \pm 0.27^{*} \\
0.33-0.64\end{array}$ & $\begin{array}{l}0.52 \pm 0.12^{* * *} \\
0.42-0.62\end{array}$ & $\begin{array}{l}0.79 \pm 0.16^{* *}+\dagger+t \\
0.67-0.93\end{array}$ \\
\hline Caspase-3(PEI) & $0.10 \pm 0.02 \dagger \dagger+t$ & $0.24 \pm 0.03 * *$ & $0.22 \pm 0.02 * *$ & $0.17 \pm 0.03 * *+\dagger \dagger$ \\
\hline $\mathrm{CI}$ & $0.08-0.12$ & $0.21-0.27$ & $0.20-0.23$ & $0.14-0.20$ \\
\hline
\end{tabular}

but another report demonstrated that pentobarbital did not increase the extent of infarction in rabbits. ${ }^{20}$ It could be disputed that the anesthetic protocol using sodium pentobarbital might have influenced our results, however, we showed that emulsified isoflurane could successfully execute a cardioprotective effect in the presence of sodium pentobarbital. Furthermore, identical anesthetic protocols were adopted in our study; thus, it is logical to consider that pentobarbital was not capable of producing different influences on parameters measured among groups. Additionally, intralipid emulsion, used to dissolve liquid isoflurane, was also investigated in this study in order to eradicate its potential influence. We found that only emulsified isoflurane, not intralipid, protected hearts. However, our results contrast with reports concerning the cardioprotective effect of intralipid. ${ }^{21,22}$ The discrepancy may result from differences in the administration protocol, the concentration of medications, and the experimental design. In this study with the same anesthetic protocol, we could not detect marked differences between the intralipid and the control group variables; therefore, by extrapolation, we conclude that emulsified isoflurane acts to protect the heart.

Although the precise mechanisms involved in the emulsified isoflurane-induced cardioprotection are not well characterized, evidence from this study confirms some important elements. Apoptosis, the crucial cellular event involved in the pathogenesis of myocardial I/R injury, is dominated by numbers of regulating genes and triggered by apoptotic signals in the development of myocardial ischemia. ${ }^{23} \mathrm{Bcl}-2$ and Bax are homologous proteins that have opposing effects on regulating apoptosis. Bcl-2, the 26-kDa anti-apoptotic protein that localizes in the outer mitochondrial membrane, and its family consist of Bcl-2, Bcl-x, Bcl-w, Bax, and Bak. ${ }^{24} \mathrm{Bcl}-2$ was considered to be the most important gene that prolongs cell survival by modulating the release of cytochrome $\mathrm{C}$ and deleterious calcium. ${ }^{25,26}$ Recent studies have demonstrated that the 
Fig. 5 Effect of emulsified isoflurane on apoptotic myocytes detected by the terminal transferase dUTP nickend labelling (TUNEL) technique in the area of myocardium at risk in sham group (sham), control group (CON), 30\% intralipid group (IL), and emulsified isoflurane group (EIso), respectively (magnification $400 \times$ ). a Rats were subjected to $30 \mathrm{~min}$ ischemia followed by $3 \mathrm{~h}$ of reperfusion. TUNEL-positive (dark brown) cardiomyocytes were regarded as apoptotic cells. Positive cells were not detected in the non-ischemic zone after ischemia and reperfusion. Box-plot graph showing the averaged percentage of TUNEL-positive cells in the ischemic regions of LVs. b Each group $n=8$. Data are expressed as mean $\pm \mathrm{SD}$. $* P<0.05,{ }^{*} * P<0.01$ compared with the sham group; ${ }^{\dagger} P<0.01$ compared with the CON group; ${ }^{*} P<0.01$ compared with the IL group a
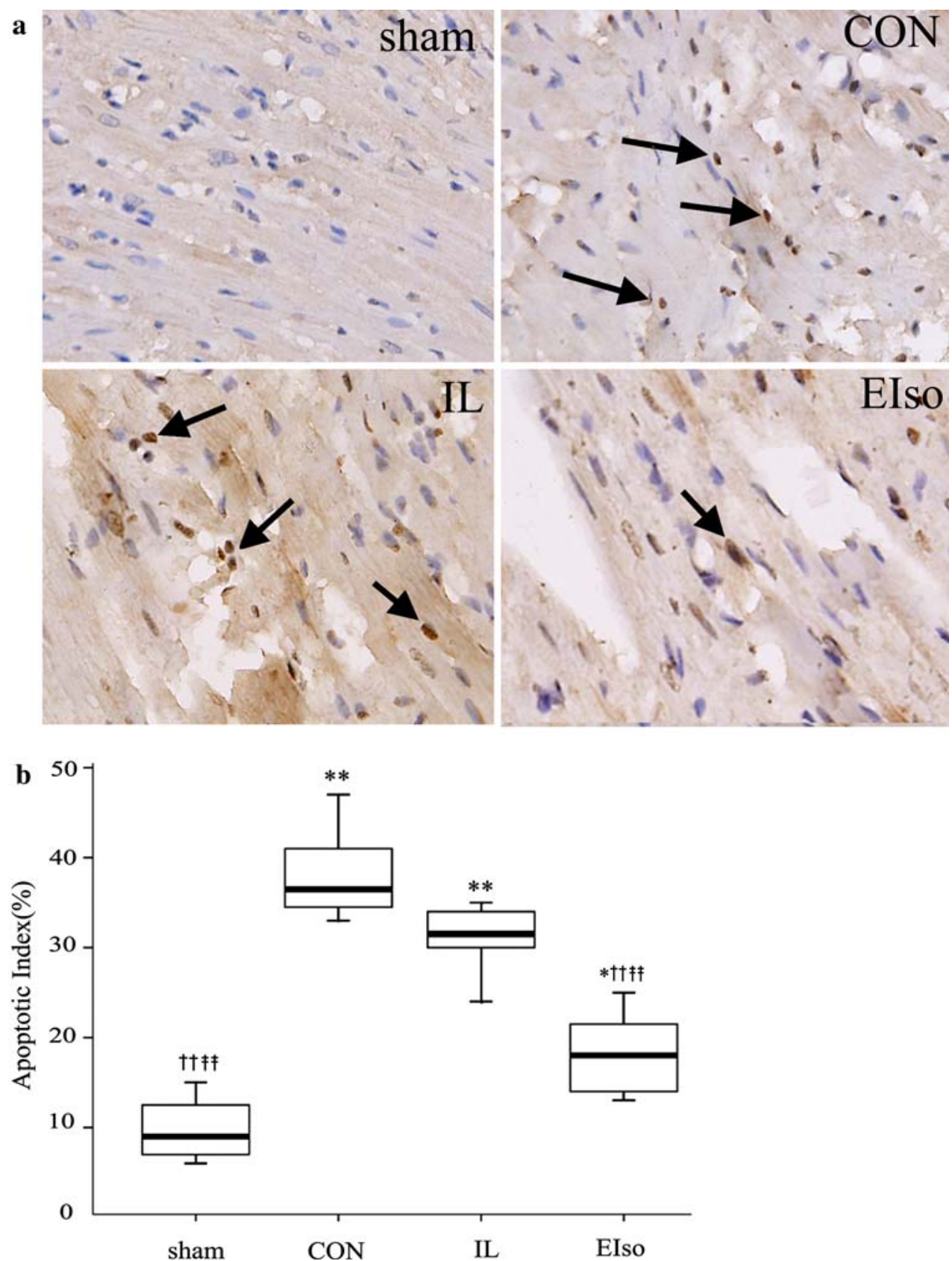

overexpression of Bcl-2 in cardiomyocytes suppresses I/R injury in transgenic mice. ${ }^{27}$ By contrast, pro-apoptotic Bax serves as an inducer of apoptosis to counteract the action of $\mathrm{Bcl}-2$, and the ratio of $\mathrm{Bcl}-2 / \mathrm{Bax}$ determines cell survival or death. ${ }^{28}$ A limited number of previous studies have shown that isoflurane may be capable of protecting hearts against apoptosis. The protective effects result from the modulation of the expression of pro- and anti-apoptotic proteins, specifically Bcl-2 and Bax. ${ }^{8,29}$ Our study extends these findings by showing that emulsified isofluraneinduced protection against I/R injury occurs concomitantly with increases in Bcl-2 protein expression and decreases in Bax protein expression, resulting in an increased $\mathrm{Bcl}-2 / \mathrm{Bax}$ ratio. Caspase family members are involved in the initiation and execution phases of apoptosis at different stages of the apoptotic pathways. Caspases-3, in particular, is considered to play a key role in mediating apoptotic cell death in the final degradation phase via the mitochondria disruption-mediated stress pathway and the death receptormediated pathway. After $180 \mathrm{~min}$ of reperfusion, we found that Caspase-3 expression in the myocardium at risk is attenuated by the exposure of emulsified isoflurane before LAD occlusion. In agreement with our findings, previous observations have demonstrated that the expression of Caspase- 3 is reduced by anesthetic-induced preconditioning. ${ }^{30}$ Furthermore, Caspase- 3 has been shown to mediate 
the cleavage of Bcl-2 to a Bax-like death effector and cytochrome $\mathrm{c}$ release in the apoptosis signalling cascade. $^{31,32}$ In combination, these observations raise the possibility that, in the preconditioned heart in our model, emulsified isoflurane may not only increase Bcl-2 expression but may also block Caspase-3 expression to prevent direct $\mathrm{Bcl}-2$ cleavage, facilitating $\mathrm{Bcl}-2$ up-regulation as a stress response to myocardial ischemia-induced myocyte apoptosis.

The mechanisms responsible for the beneficial effects of emulsified isoflurane-induced preconditioning have yet to be firmly established. Isoflurane preconditioning is potentially achieved by several mediators and pathways. The phosphatidylinositol-3-kinase (PI3K)/Akt pathway plays an important role in this process and has emerged as a critical regulator of apoptosis. PI3K converts phosphatidylinositol4,5-bisphosphate to phosphatidylinositol-3,4,5-trisphosphate, ${ }^{33}$ which further activates signalling proteins, including serine-threonine kinases of the Akt family. Subsequently, Akt phosphorylates and inhibits apoptoticrelated substrates, including Bax, Caspase 9, and Bad. It has been indicated that the PI3K/Akt signalling pathway has been involved in isoflurane-induced preconditioning ${ }^{34}$ and postconditioning. ${ }^{35}$ Additionally, apart from rendering the myocardium resistant to $\mathrm{I} / \mathrm{R}$ injury, preconditioning also potentiates angiogenesis. ${ }^{36}$ Hypoxia inducible factor 1 (HIF-1) serves to promote vascular endothelial growth factor (VEGF) gene expression; thus, it ultimately triggers the cascade of angiogenesis. HIF-1 activity depends on the amount of HIF- $1 \alpha$ protein. ${ }^{37}$ Few studies regarding HIF- $1 \alpha$ have been reported in association with cardiac myocytes. A study by Kim et al. ${ }^{38}$ showed that enhanced expression of both HIF- $1 \alpha$ and its downstream VEGF occurs during myocardial ischemia in rats. Moreover, HIF- $1 \alpha$ expression is also associated with enhanced VEGF activation in the human heart during ischemia. ${ }^{39}$ Furthermore, isoflurane has also been shown to reduce infarct size concomitant with upregulation of HIF- $1 \alpha$ and VEGF in rats. ${ }^{40}$ Although the involvement of PI3K/Akt in the HIF pathway remains controversial, Akt and HIF-1 have been shown to share the ability to induce VEGF and to promote angiogenesis. HIF$1 \alpha$ expression is up-regulated through the PI3K/Akt pathway. ${ }^{38}$ In contrast, it has been reported that activation of the PI3K/Akt pathway does not affect HIF-mediated transcription under normoxic or hypoxic conditions. ${ }^{41}$ The reason for this discrepancy may be attributed to the cell type and the different experimental conditions. However, these previous data evoke the intriguing hypothesis that the PI3K/ Akt cascade signalling pathway and the HIF pathway may also mediate emulsified isoflurane-induced protection against I/R injury. Further research in this area is merited.

Concentrations of $\mathrm{LDH}$ and $\mathrm{CK}$ in plasma are indicators of cell injury. High LDH and CK activity levels in the
CON and IL groups may be interpreted as a progression of cell injury; therefore, the decrease of LDH and CK release after emulsified isoflurane treatment may be indicative of decreased cell injury. This study is in accordance with the recent observation that emulsified isoflurane pretreatment leads to a significant decrease in LDH and CK activity after reperfusion, indicating amelioration of cell injury. ${ }^{4}$ Taken together, these data suggest that the decrease of infarct size and the reduction of LDH and CK release was accompanied by the inhibition of apoptosis in emulsified isofluranetreated hearts, which may contribute to the mechanism of emulsified isoflurane-induced cardioprotection.

We acknowledge several limitations of this study. First, blood concentrations of isoflurane during infusion and immediately before LAD occlusion were not measured in this investigation; therefore, the unequal dose of isoflurane administered to the rats cannot be absolutely excluded as a factor involved in myocardial ischemia. Second, we did not monitor the $\mathrm{pH}, \mathrm{pO}_{2}$, and $\mathrm{pCO}_{2}$ in this experiment, since the measurement of blood gas permits the diagnosis of metabolic and respiratory acidosis as well as oxygenation; thus, it remains unknown whether these parameters can affect the production and release of reactive oxygen species during and after the administration of emulsified isoflurane.

In conclusion, the current results demonstrate that intravenous administration of emulsified isoflurane (8\% Vol/Vol) $2 \mathrm{ml} \mathrm{kg}^{-1}$ before coronary artery occlusion affords an effective protection against myocardial I/R injury in rats, which may occur as a consequence of inhibiting myocardial damage and apoptosis. The relative contribution of the mechanisms of emulsified isofluraneinduced cardioprotection remains to be elucidated; then again, the current therapeutic approaches may facilitate using halogenated ethers designed for organ protection for patients with coronary artery disease in clinical fields.

Acknowledgements This study was supported by grant No. 2005CB522601 from the 973 Program, Beijing, China and grant No. 30772084 from the National Research Foundation of Nature Sciences, Beijing, China.

Conflicts of interest None declared.

\section{References}

1. Toller WG, Kersten JR, Pagel PS, Warltier DC. Ischemic preconditioning, myocardial stunning and anesthesia. Curr Opin Anaesthesiol 2000; 13: 35-40.

2. Tanaka K, Ludwig LM, Kersten JR, Pagel PS, Warltier DC. Mechanisms of cardioprotection by volatile anesthetics. Anesthesiology 2004; 100: 707-21.

3. Chiari PC, Pagel PS, Tanaka K, et al. Intravenous emulsified halogenated anesthetics produce acute and delayed preconditioning against myocardial infarction in rabbits. Anesthesiology 2004; 101: 1160-6. 
4. Rao Y, Wang YL, Zhang WS, Liu J. Emulsified isoflurane produces cardiac protection after ischemia-reperfusion injury in rabbits. Anesth Analg 2008; 106: 1353-9.

5. Piot CA, Padmanaban D, Ursell PC, Sievers RE, Wolfe CL. Ischemic preconditioning decreases apoptosis in rat hearts in vivo. Circulation 1997; 96: 1598-604.

6. Zhao ZQ, Vinten-Johansen J. Myocardial apoptosis and ischemic preconditioning. Cardiovasc Res 2002; 55: 438-55.

7. Zaugg M, Jamali NZ, Lucchinetti E, Shafiq SA, Siddiqui MA. Norepinephrine- induced apoptosis is inhibited in adult rat ventricular myocytes exposed to volatile anesthetics. Anesthesiology 2000; 93: 209-18.

8. Jamnicki-Abegg M, Weihrauch D, Pagel PS, et al. Isoflurane inhibits cardiac myocyte apoptosis during oxidative and inflammatory stress by activating Akt and enhancing Bcl-2 expression. Anesthesiology 2005; 103: 1006-14.

9. Zhou JX, Luo NF, Liang XM, Liu J. The efficacy and safety of intravenous emulsified isoflurane in rats. Anesth Analg 2006; 102: 129-34.

10. Yang $X L$, Ma $H X$, Yang $Z B$, et al. Comparison of minimum alveloar concentration between intravenous isoflurane lipid emulsion and inhaled isoflurane in dogs. Anesthesiology 2006; 104: 482-7.

11. Keselman HJ, Keselman JC. The analysis of repeated measures designs in medical research. Stat Med 1984; 3: 185-95.

12. Warltier DC, al-Wathiqui MH, Kampine JP, Schmeling WT. Recovery of contractile function of stunned myocardium in chronically instrumented dogs is enhanced by halothane or isoflurane. Anesthesiology 1988; 69: 552-65.

13. De Hert SG, Turani F, Mathur S, Stowe DF. Cardioprotection with volatile anesthetics: mechanisms and clinical implications. Anesth Analg 2005; 100: 1584-93.

14. Pratt PF Jr, Wang C, Weihrauch D, et al. Cardioprotection by volatile anesthetics: new applications for old drugs? Curr Opin Anaesthesiol 2006; 19: 397-403.

15. Preckel B, Schlack W, Comfère T, Obal D, Barthel H, Thamer V. Effects of enflurane, isoflurane, sevoflurane and desflurane on reperfusion injury after regional myocardial ischaemia in the rabbit heart in vivo. Br J Anaesth 1998; 81: 905-12.

16. Ludwig LM, Patel HH, Gross GJ, Kersten JR, Pagel PS, Warltier $D C$. Morphine enhances pharmacological preconditioning by isoflurane: role of mitochondrial K(ATP) channels and opioid receptors. Anesthesiology 2003; 98: 705-11.

17. Tanaka K, Weihrauch D, Kehl F, et al. Mechanism of preconditioning by isoflurane in rabbits: a direct role for reactive oxygen species. Anesthesiology 2002; 97: 1485-90.

18. Kersten JR, Schmeling TJ, Pagel PS, Gross GJ, Warltier DC. Isoflurane mimics ischaemic preconditioning via activation of KATP channels: reduction of myocardial infarct size with an acute memory phase. Anesthesiology 1997; 87: 361-70.

19. Yang XP, Liu YH, Rhaleb NE, Kurihara N, Kim HE, Carretero $O A$. Echocardiographic assessment of cardiac function in conscious and anesthetized mice. Am J Physiol 1999; 277: H196774.

20. Cope DK, Impastato WK, Cohen MV, Downey JM. Volatile anesthetics protect the ischemic rabbit myocardium from infarction. Anesthesiology 1997; 86: 699-709.

21. Oliver $M F$. Prevention of ventricular fibrillation during acute myocardial ischemia: control of free fatty acids. J Cardiovasc Pharmacol Ther 2001; 6: 213-7.

22. Kurien VA, Oliver $M F$. Free fatty acids during acute myocardial infarction. Prog Cardiovasc Dis 1971; 13: 361-73.

23. Gottlieb RA, Engler RL. Apoptosis in myocardial ischemia-reperfusion. Ann NY Acad Sci 1999; 874: 412-26.

24. Krajewski S, Tanaka S, Takayama S, Schibler MJ, Fenton W, Reed JC. Investigation of the subcellular distribution of the bcl-2 oncoprotein: residence in the nuclear envelope, endoplasmic reticulum, and outer mitochondrial membranes. Cancer Res 1993; 53: 4701-14.

25. Kluck RM, Bossy-Wetzel E, Green DR, Newmeyer DD. The release of cytochrome $\mathrm{c}$ from mitochondria: a primary site for Bcl-2 regulation of apoptosis. Science 1997; 275: 1132-6.

26. Foyouzi-Youssefi $R$, Arnaudeau $S$, Borner $C$, et al. Bcl-2 decreases the free $\mathrm{Ca}^{2+}$ concentration within the endoplasmic reticulum. Proc Natl Acad Sci USA 2000; 97: 5723-8.

27. Tanaka M, Nakae S, Terry RD, et al. Cardiomyocyte-specific Bcl2 overexpression attenuates ischemia-reperfusion injury, immune response during acute rejection, and graft coronary artery disease. Blood 2004; 104: 3789-96.

28. Kroemer G, Dallaporta B, Resche-Rigon M. The mitochondrial death/life regulator in apoptosis and necrosis. Annu Rev Physiol 1998; 60: 619-42.

29. Raphael J, Abedat S, Rivo J, et al. Volatile anesthetic preconditioning attenuates myocardial apoptosis in rabbits after regional ischemia and reperfusion via Akt signaling and modulation of Bcl-2 family proteins. J Pharmacol Exp Ther 2006; 318: 186-94.

30. Tsutsumi YM, Patel HH, Lai NC, Takahashi T, Head BP, Roth $D M$. Isoflurane produces sustained cardiac protection after ischemia-reperfusion injury in mice. Anesthesiology 2006; 104: 495502.

31. Cheng EH, Kirsch DG, Clem RJ, et al. Conversion of Bcl-2 to a Bax-like death effector by caspases. Science 1997; 278: 1966-8.

32. Kim YM, Kim TH, Seol DW, Talanian RV, Billiar TR. Nitric oxide suppression of apoptosis occurs in association with an inhibition of Bcl-2 cleavage and cytochrome c release. J Biol Chem 1998; 273: 31437-41.

33. Cantley LC. The phosphoinositide 3-kinase pathway. Science 2002; 296: 1655-7.

34. Raphael J, Rivo J, Gozal Y. Isoflurane-induced myocardial preconditioning is dependent on phosphatidylinositol-3-kinase/Akt signaling. Br J Anaesth 2005; 95: 756-63.

35. Chiari PC, Bienengraeber MW, Pagel PS, Krolikowski JG, Kersten JR, Warltier DC. Isoflurane protects against myocardial infarction during early reperfusion by activation of phosphatidylinositol-3-kinase signal transduction: evidence for anestheticinduced postconditioning in rabbits. Anesthesiology 2005; 102: 102-9.

36. Maulik N. Ischemic preconditioning mediated angiogenic response in the heart. Antioxid Redox Signal 2004; 6: 413-21.

37. Huang LE, Gu J, Schau M, Bunn HF. Regulation of hypoxiainducible factor 1alpha is mediated by an $\mathrm{O}_{2}$-dependent degradation domain via the ubiquitin-proteasome pathway. Proc Natl Acad Sci USA 1998; 95: 7987-92.

38. Kim CH, Cho YS, Chun YS, Park JW, Kim MS. Early expression of myocardial HIF-1alpha in response to mechanical stresses: regulation by stretch-activated channels and the phosphatidylinositol 3-kinase signaling pathway. Circ Res 2002; 90: E25-33.

39. Lee SH, Wolf PL, Escudero R, Deutsch R, Jamieson SW, Thistlethwaite PA. Early expression of angiogenesis factors in acute myocardial ischemia and infarction. N Engl J Med 2000; 342: 626-33.

40. Wang C, Weihrauch D, Schwabe DA, et al. Extracellular signalregulated kinases trigger isoflurane preconditioning concomitant with upregulation of hypoxia-inducible factor-1alpha and vascular endothelial growth factor expression in rats. Anesth Analg 2006; 103: 281-8.

41. Alvarez-Tejado M, Alfranca A, Aragones J, Vara A, Landazuri $M O$, del Peso L. Lack of evidence for the involvement of the phosphoinositide 3-kinase/Akt pathway in the activation of hypoxia-inducible factors by low oxygen tension. J Biol Chem 2002; 277: 13508-17. 